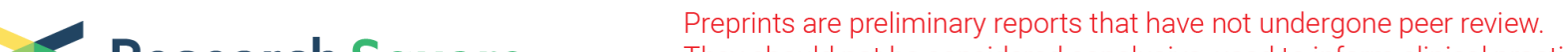 Research Square
or referenced by the media as validated information.
}

\section{Strategy to preserve function in lower limbs tumors resection. Vascular competence in multidisciplinary approach}

\section{Andrea Ascoli Marchetti ( $\square$ ascolimarchetti@med.uniroma2.it)}

Universita degli Studi di Roma Tor Vergata https://orcid.org/0000-0001-9229-0495

\section{Lorenzo Di Giulio}

Vascular Surgery Unit, Biomedicine Prevention Department. University of Rome Tor Vergata. Rome, Italy

\section{Fabio Massimo Oddi}

Vascular surgery Unit. Biomedicine and Prevention Department. University of Rome Tor Vergata

\section{Bernardo Orellana Davila}

Universita degli Studi di Roma Tor Vergata Dipartimento di Medicina Sperimentale e Chirurgia

\section{Riccardo Ciattaglia}

Vascular Surgery Unit. Biomedicine and Prevention Department. University of Rome Tor Vergata. Rome, Italy

\section{Arnaldo Ippoliti}

Vascular Surgery Unit. Biomedicine and Prevention Department. University of Rome Tor Vergata. Rome. Italy

\section{Research}

Keywords: sarcoma, limbs sparing, artery reconstruction, vein reconstruction

Posted Date: April 20th, 2020

DOI: https://doi.org/10.21203/rs.3.rs-22587/v1

License: (c) (i) This work is licensed under a Creative Commons Attribution 4.0 International License. Read Full License 


\section{Abstract}

\section{Introduction}

All possible strategy should be adopted to preserve limb function during the definitive removal operation in the case of limbs sarcoma. Multidisciplinary perspective seems to be the ideal choice. The aim of the study is to report our experience gained in collaboration with the IFO oncology orthopedic division and with the operating units of Orthopedics $A$ and $B$ of our institution, reporting the type of intervention, results and complications of the procedures performed.

\section{Material and methods}

From 2011 to 2019, were treated 32 patients affected by primitive and secondary musculoskeletal neoplasm with a mean age of 44 years (14-67 years) in 28 cases (87.5\%) were required revascularization. Women accounted for $46.9 \%$ (15/32), 53.1\% were men (17/32). The preoperative study included a biopsy of the lesion and ultrasonography and CTA with multiplanar reconstructions for the evaluation of the vascular anatomy and neoplasia extension.

\section{Results}

The average postoperative follow-up was 20.1 months. The reconstruction of the vessels has been implemented in 14/32 (43.7\%) mainly using the autologous saphenous contralateral vein. The use of the prosthesis was performed in the others cases (with PTFE and Dacron K prosthesis). In 5 cases (15.6\%) the patients had lower limb edema, with a distance venous patency of $26 / 32(81.2 \%)$ and arterial patency of $100 \%$. We had no mortality at 30 days. Two patients underwent VAC therapy. No amputations were performed at 30 days. In 14 patients was performed perioperative chemotherapy or radiotherapy.

\section{Conclusions}

A long-term evaluation is needed to determine the implications at distance, in patients undergoing radical resection of cancer in which are necessary for skills vascular surgery. The long term result is conditioned by the prognosis of neoplasm. The multidisciplinary approach is always requested.

\section{Introduction}

The vascular management of patients affected by resectable neoplasm provides the use of principles of oncovascular surgery in operative planning, particularly when preparing for a ligation with complete removal or when performing an arterial or venous reconstruction.

In patients with lower limb soft tissue sarcomas the presence of involvement of the neurovascular structures is $3 \%$. Although it is therefore a rare necessity, this type of involvement requires vascular surgery skills that must be considered. $(1,2)$

\section{Methods}


In a four years period from 2011 to 2019, in our center were treated 32 patients affected by primitive and secondary musculoskeletal neoplasm with a mean age of 44 years (14-67 years) in 28 cases (87.5\%) were required revascularization. Women accounted for $46.9 \%$ (15/32), 53.1\% were men (17/32). The preoperative study included a biopsy of the lesion and ultrasonography and CTA with multiplanar reconstructions for the evaluation of the vascular anatomy, neoplasia extension and a consequent accurate planning of the intervention after oncological, orthopedic and vascular surgery opinion.

\section{Results}

The reconstruction of the vessels has been implemented in 14/32 (43.7\%) mainly using the autologous saphenous contralateral vein. The use of the prosthesis was performed in the others cases (with PTFE and Dacron $\mathrm{K}$ prosthesis). In 5 cases $(15.6 \%$ ) the patients had lower limb edema, with a distance venous patency in $26 / 32(80 \%)$ and arterial patency of $100 \%$. No mortality at 30 days was found. Two patients underwent VAC therapy. In one case transplantation of bone was associated. No amputations were performed at 30 days. The average postoperative follow-up was 20.1 months. In 14 patients was performed perioperative chemotherapy or radiotherapy. $4 / 14(28.5 \%)$ presented a asymptomatic occlusion of the vein graft. Compression therapy is indicated with a very good results.

\section{Discussion}

The first reported case of vascular reconstruction associated with lower limb sarcoma resection is described by Fortner in 1977, (3) the concept of limbs preserving surgery has been progressively adopted, when possible, for the improvement of the quality of life. $(4,5)$

\section{Multidisciplinary approach}

This objective should be achieved in all invasive neoplasm with vascular involvement with a close collaboration between all the specialists. The decision-making process in lower limbs soft tissue sarcoma is crucial and include oncologist, orthopedic and vascular specialists for a preoperative planning and cooperation also in the postoperative period. (6)

Lower limb soft tissue sarcoma can be rarely removed preserving the arterial and venous vessels, because major vascular resection and reconstruction is required for adequate oncologic margins. The excision with artery and/or vein reconstruction has been already reported. (7) For example, in our series, in a male patient 41 years old, affected by symptomatic neoplasm after local radiotherapy and vascular compression, it discussed which type of resection should be more appropriate. It was performed a "partial resection" with bone transplantation and vessel replacement with GSV, following discussion with oncologist and orthopedic surgeon.

(Fig 1) The histological specimen analysis reveal an intact margin preservation with absence of neoplastic cells.

Preoperative diagnostic imaging 
Preoperative vascular imaging is crucial for operative planning.

In our series all patients underwent CT angiography. This examination give, using multiplanar reconstruction, the best imaging requirements for preoperative evaluation in tumor resection surgery, accurately revealing the vascularization of the neoplasm and the relationships of contiguity or continuity between the neoplasm and the vessels. (Fig 2A)

CT gives best depiction of osseous structures and has better spatial resolution compared to MRI, despite the disadvantages of using ionizing radiation and iodine contrast medium, potentially nephrotoxic.

In all cases patients had the contralateral leg vein mapped just before the operation

to obtain precise donor site of the great saphenous vein, in case of need.

\section{Results and complication}

The surgical techniques in previous series reports mortality rates of $0-4.8 \%$, tumor control in $86-100 \%$ of patients and limb salvage in $92-94.1 \%$. (3) In the postoperative period the presence of edema was clinically evident in about $40 \%$ of treated cases, with no obvious difference between veins treated with grafting or with ligation as Schwarzbach , Tsukushi and Spark demonstrated(4,8,9). In our experience 5/32 pts presented edema postoperative with the same characteristics. Morbidity came from wound complications, with dehiscence reported in the literature 33-57\%. (10)

In our cases, this kind of complication were experience successfully treated with Vacuum Assisted Closure Therapy (VAC). The literature report a graft infection rates of $6-29 \%$. $(2,7,11)($ Tab 1$)$

No infection were observed in our experience. In this condition, when the vessel involvement and removal is crucial for a radical surgery, vascular surgeon role is essential in a multidisciplinary setting, also to choice the better technique of revascularization or to decide no indication for an eventual venous vessel replacement $(12,13)$ (Fig 3-4)

In particular cases the removal of the neoplasm may require a large dissection to preserve the vascular axis and also in the absence of a revascularization, the presence of the vascular surgeon makes the bleeding minimal and the removal more accurate and, at the same time, radical. (Fig 2B). While immediate results are influenced by intraoperative conduct, the follow-up results are conditioned by the appearance of metastases and consequent mortality is not negligible. The 5 -year survival rate is $68.4 \%$ in the more prolonged follow up. $(12,14)$

As in reconstructions for atherosclerotic obstructive pathology, the vein is used as an ideal substitute.

In our experience, in the case of unavailability of suitable venous autogenic substitutes, good results have also been obtained with synthetic prostheses with comparable rates of patency. It is necessary to consider that these are normal arteries, therefore with greater possibility of patency even at a distance. For venous reconstructions also in our experience the patency was lower, but with no relevant symptoms. The majority 
of patients must perform chemo and radiotherapy cycles and despite the good results, the mortality at distance is unpredictable, depending on the neoplasm prognosis.

\section{Conclusions}

Major vessel involvement during cancer surgery may be observed. The vascular surgeons in a multidisciplinary approach, plans the exact surgical view through the avascular plane far from neoplasm and may prevent or minimize the bleeding complications, assuring definitive result of the resection . A longterm evaluation is needed to determine the implications at distance in these patients. The necessity of vascular surgery skills is rare but essential for limb sparing. The mortality gap is conditioned by the prognosis of neoplasm.

\section{Declarations}

Availability of Data and Materials The data supporting their findings can be found in the electronic archive of our hospital and are available on request.

Competing interests The authors declare that they have no competing interests

Funding The authors declare no funds have been paid for research, for body in the design of the study and collection, analysis, and interpretation of data and in writing the manuscript.

Ethical approval The specifical ethical approval in our institution is not required because the analysis undertakes used data collected for a routine clinical care.

Informed consent for the study was obtained from all patients.

Study data and materials have been collected and are available on request.

\section{Authors contribution:}

AAM participated in the conception and desig, operations, analysis and interpretation and drafted the manuscript. Critical revision and final approval.

LDG participated in desig, operations, drafted the manuscript and final approval.

FMO participated in the desig, operations, analysis and interpretation and drafted the manuscript and final approval.

BOD participated in the data collection and analysis and final approval.

RC participated in the data collection and analysis and final approval.

Al participated in the conception and desig, operations, analysis and interpretation and drafted the manuscript. Critical revision and final approval. 
Acknowledgements The author would like to acknolege the teams of Oncological Orthopedics of IFO and Orthopedic and Traumatology A and B Unit of the Tor Vergata Policlinic, for their collaboration.

\section{References}

1. Tunn P, Kettelhack C, Dürr HR. of the Extremities. 2009;211-28.

2. Han A, Ahn S, Min S. Oncovascular Surgery: Essential Roles of Vascular Surgeons in Cancer Surgery. 2019;35(2).

3. Ghosh J, Bhowmick A, Baguneid M. Oncovascular surgery. Eur J Surg Oncol [Internet]. 2011;37(12):1017-24. Available from: http://dx.doi.org/10.1016/j.ejso.2011.08.131

4. Spark JI, Charalabidis P, Laws P, Seben R, Clayer M. Vascular reconstruction in lower limb musculoskeletal tumours. 2009;79(August 2006):619-23.

5. Bach AD, Kopp J, Stark GB, Horch RE. The versatility of the free osteocutaneous fibula flap in the reconstruction of extremities after sarcoma resection. 2004;9:1-9.

6. Fortner JG, Kim K, Shiu MH. Limb-Preserving Vascular Surgery for Malignant Tumors of the Lower Extremity Neoplasms. 1977;

7. Muramatsu K, Ihara K, Miyoshi T, Yoshida K, Taguchi T. Clinical Outcome of Limb-Salvage Surgery After Wide Resection of Sarcoma and Femoral Vessel Reconstruction. Ann Vasc Surg [Internet]. 2011;25(8):1070-7. Available from: http://dx.doi.org/10.1016/j.avsg.2011.05.009

8. Schwarzbach MHM, Hormann Y, Hinz U, Bernd L. Results of limb-sparing surgery with vascular replacement for soft tissue sarcoma in the lower extremity. 2003;(January 1988):88-97.

9. Tsukushi S, Nishida Y, Sugiura H. Results of Limb-Salvage Surgery With Vascular Reconstruction For Soft Tissue Sarcoma in the Lower Extremity: Comparison Between Only Arterial and Arterovenous Reconstruction. 2008;(December 2007):216-20.

10. Song TK, Jr EJH, Raghavan S, Norton JA. Major Blood Vessel Reconstruction During Sarcoma Surgery. 2015;144(9):817-22.

11. Nishinari K, Wolosker N, Yazbek G, Zerati AE, Nishimoto IN, Paulo S. Venous reconstructions in lower limbs associated with resection of malignancies. :1046-50.

12. Cetinkaya OA, Celik SU, Kalem M, Basarir K, Koksoy C, Yildiz HY. SC. Ann Vasc Surg [Internet]. 2018; Available from: https://doi.org/10.1016/j.avsg.2018.09.018

13. Sormaz C, Aksoy M, Ozger H, Eralp L. Acta Orthopaedica et Traumatologica Turcica Results and functional outcomes of en-bloc resection and vascular reconstruction in extremity musculoskeletal tumors. 2018;

14. Radaelli S, Fiore M, Colombo C, Ford S, Palassini E, San R, et al. Vascular resection en-bloc with tumor removal and graft reconstruction is safe and effective in soft tissue sarcoma ( STS ) of the extremities and retroperitoneum. 2016;25.

15. Karakousis CP. Refinements of Surgical Technique in Soft Tissue Sarcomas. 2010;(February):730-8.

16. Motamedi M, Hons BA, Temple W. Vascular Reconstruction With the Superficial Femoral Vein Following Major Oncologic Resection. 2007;(October 2006):151-9. 
17. Davis LA, Dandachli F, Turcotte R, Steinmetz OK. Limb-sparing surgery with vascular reconstruction for malignant lower extremity soft tissue sarcoma. J Vasc Surg [Internet]. :1-6. Available from: http://dx.doi.org/10.1016/j.jvs.2016.05.094

18. Ascoli Marchetti A, Di Giulio L, Citoni G, Ippoliti A Oncovascular Surgery-The Multidisciplinary Approach: Surgical Resection of the Musculoskeletal Tumor and Associated Revascularization J Surg Res 2019; 2 (3): Journal of Surgery and Research147-153 DOI: 10.26502/jsr.10020031 J 147

\section{Tables}

Tab 1 Literature review on vascular reconstructions in musculoskeletal tumor of the limbs.

\begin{tabular}{|c|c|c|c|c|c|c|c|c|c|}
\hline Author & Period & Pts & $\begin{array}{l}\text { Mean } \\
\text { Follow } \\
\text { up } \\
\text { (months) }\end{array}$ & $\begin{array}{l}\text { Artery/ } \\
\text { involve } \\
\text { and } \\
\%\end{array}$ & $\begin{array}{l}\text { vein } \\
\text { ement }\end{array}$ & $\begin{array}{c}\begin{array}{l}\text { Artery } \\
\text { patency }\end{array} \\
30 \\
\text { day } \%\end{array}$ & $\begin{array}{l}\text { Local } \\
\text { Infection } \\
\text { Pts (n) } \\
\%\end{array}$ & $\begin{array}{l}\text { Mortality } \\
30 \text { day }\end{array}$ & $\begin{array}{l}\text { Morbidity } \\
\text { (pts) } \\
\text { and \% }\end{array}$ \\
\hline $\begin{array}{l}\text { Karakousis } \\
\text { (15) }\end{array}$ & $\begin{array}{l}1991- \\
1996\end{array}$ & 21 & 60 & $7 / 21$ & 33.0 & 100 & $\begin{array}{l}(5) \\
24 . \%\end{array}$ & 0 & $\mathrm{nr}$ \\
\hline McKay (16) & $\begin{array}{l}2002- \\
2005\end{array}$ & 7 & 20.2 & $7 / 7$ & 100 & 100 & 0 & 0 & $\begin{array}{l}(5 / 7) \\
78\end{array}$ \\
\hline Spark (4) & $\begin{array}{l}2002- \\
2006\end{array}$ & 9 & 19.1 & $8 / 9$ & 88.8 & 100 & $\mathrm{nr}$ & 0 & $\begin{array}{l}(3 / 9) \\
33.3\end{array}$ \\
\hline $\begin{array}{l}\text { Akgül T } \\
\text { (13) }\end{array}$ & $\begin{array}{l}2004- \\
2007\end{array}$ & 15 & 39 & $12 / 15$ & 80 & 82.4 & $\begin{array}{l}(5) \\
29.4 \%\end{array}$ & - & $\mathrm{nr}$ \\
\hline Song (10) & $\begin{array}{l}2003- \\
2008\end{array}$ & 14 & 36 & $7 / 14$ & 50.0 & 83 & 0 & 0 & $\mathrm{nr}$ \\
\hline Emory & $\begin{array}{l}1997- \\
2009\end{array}$ & 10 & 48 & $10 / 10$ & 100 & 90 & 0 & 0 & $\begin{array}{c}(6 / 10) \\
60\end{array}$ \\
\hline $\begin{array}{l}\text { Muramatsu } \\
\text { (7) }\end{array}$ & $\begin{array}{l}1995- \\
2010\end{array}$ & 15 & 71.8 & $15 / 15$ & 100 & 93.3 & $\begin{array}{l}(1) \\
6 \%\end{array}$ & 0 & $\begin{array}{c}(9 / 15) \\
60\end{array}$ \\
\hline Davis (17) & $\begin{array}{l}2005- \\
2013\end{array}$ & 9 & 74.7 & $1 / 9$ & 11.1 & $\mathrm{nr}$ & $\mathrm{nr}$ & 0 & $\begin{array}{l}(7 / 9) \\
77.8\end{array}$ \\
\hline $\begin{array}{l}\text { Cetinkaya } \\
\text { (12) }\end{array}$ & $\begin{array}{l}2002- \\
2014\end{array}$ & 13 & 80.6 & $\begin{array}{l}13 / 13 \\
100 \%\end{array}$ & & 84.6 & $\begin{array}{l}(3) \\
23.1 \%\end{array}$ & 0 & $\begin{array}{l}(9 / 13) \\
69.2^{\star}\end{array}$ \\
\hline $\begin{array}{l}\text { Our } \\
\text { Experience }\end{array}$ & $\begin{array}{l}2011- \\
2019\end{array}$ & 32 & 20.1 & $\begin{array}{l}14 / 32 \\
43.7\end{array}$ & & 100 & (2) $6.6 \%$ & 0 & $\begin{array}{l}(4 / 32) \\
12.5\end{array}$ \\
\hline
\end{tabular}

nr: not reported *cumulative data

\section{Figures}




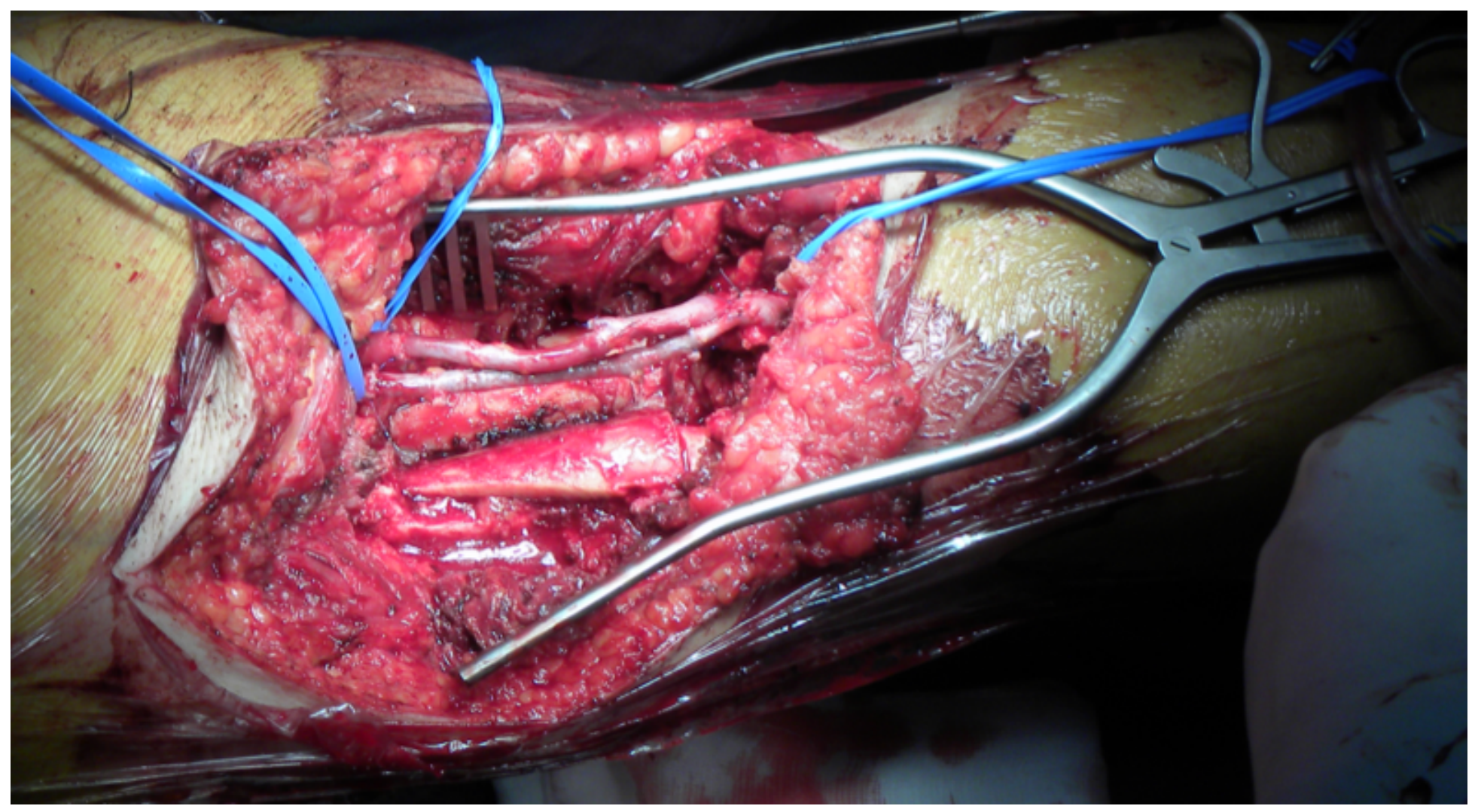

\section{Figure 1}

Intraoperative image. Prone patient. Posterior view. The scalpel just resected the neoplasia. The red arrow indicate the superficial femoral artery (Great saphenous vein inverted) and vein (Great saphenous vein) . The blue arrow indicate the bone transplanted after partial femoral bone excision. 展

\section{Figure 2}

A: Preoperative CT scan: Note the bone erosion and vessel compression. 2B: intraoperative specimen of neoplasm after the surgical removal.

要

\section{Figure 3}

Intraoperative image. The scalpel resets the neoplasia proximally. The non involved vessels are clamped. The arrow indicates the superficial femoral artery and vein to the left of the scalpel (18) A

\section{Figure 4}

Intraoperative image. The superficial femoral artery and the superficial femoral vein are removed with the sarcoma. A IGVS (inverted great safenous vein) has been grafted to replace the removed artery tract. The VSA (great safenous vein) has been grafted to replace the removed vein tract. (18) 